\title{
An Analysis of "Jordan Opportunities" Objectives in the General Secondary Certificate Examination of English: A Case Study in Jordan between 2008 and 2010
}

\author{
Dr. Mahmoud Sulaiman Bani Abdelrahman \\ Assistant Professor \\ Al - Hussein Bin Talal University, Jordan \\ E-mail: Abugaith66@yahoo.com
}

\begin{abstract}
The study aimed at investigating the GSCE through assessing to what extent English Language Teaching Objectives are available in the GSCE in Jordan between 2008 and 2010.This study attempts to answer the following questions:

1- To what extent are the English language Teaching objectives realized in the GSCE in Jordan between 2008 and 2010 for each academic year?

2- To what extent are the English language Teaching objectives realized in the GSCE in Jordan between 2008 and 2010 for all the three years collectively?
\end{abstract}

The sample of the study consists of all examination papers of the GSCE in English in Jordan between the years 2008 and 2010. For the purpose of the study, the researcher developed a questionnaire that consists of 13 Thirston -type items that were classified under the following categories:

1 - listening 2

2- speaking 3

3- reading 3

4 - writing 5

The questionnaire was prepared in English. The questionnaire was given to a jury of professors, supervisors and teachers of English. The jury's responses on the questionnaire were analyzed as follows:

1- $\quad$ Percentage and frequency in each response category.

2- $\quad$ Basic descriptive statistical mean and standard deviation.

3- Phi and Cramer's V for nominal variables (corresponding internal contingency coefficient in case of interval variables) Using the Statistical Package for Social Studies (SPSS) uses the above-mentioned procedure.

The study presents the following

1- The objectives of listening and speaking are not available in the GSCE completely.

2- Two out of three of the reading objectives are available.

3- Four out of five of the writing objectives are available in the GSCE.

On the basis of the findings, the researcher recommended the following:

1- Include speaking and listening exams in the GSCE because of the need to let teachers teach them in classes.

2- Vary the questions of reading and writing to cover all the objectives.

3- To test what we teach not to teach what we are going to test as the case in most schools.

Keywords: Jordan opportunities, Objectives, e (GSCE) General Secondary Certificate Examination

\section{Introduction}

Jordan, a country blessed with diverse human resources, has exerted numerous efforts to improve the quality of its educational system. The most significant step in this regard was the first National Conference for Educational 
Development in 1987 which re-assessed the operating educational system. The conference convened to overhaul the Jordanian public system into two stages. The Basic Education Stage covers the first ten years and the Secondary Education Stage covers the final two years.

Jordan Opportunities is a multi-level course that has been specially designed for Jordanian students learning English in grades 10,11, and 12. The basic premise of the course is that secondary students learn English best when they are dealing with interesting and meaningful content. Thematic input provides a context for language and communication, and supplies a series of cognitive 'anchors' for learning which are crucial in a monolingual learning environment. Jordan Opportunities 3 for twelfth grade is a two-level course, organized into six topic-based modules. The first level covers learning to learn and modules 1,2 and 3 . The second level covers modules 4,5 and 6 .

Within each module there are different sub-topics, which provide variety and at the same time explore the module theme in depth. Each topic offers opportunities to explore three kinds of content.
a- Topics related to the student's own world.
b- Cross-curricula themes.
c- Cultural input. (Harris, M; Mower, D and Sikorzynska, A, 2007)

In light OF Jordan opportunities series, the Ministry of Education in Jordan (2008:2) stated that students are expected to acquire a variety of skills and to achieve the following objectives:

\section{A-Listening}

1-Develop advanced listening strategies in academic and authentic contexts.

2- Demonstrate understanding of directions, presentations and performances in a variety of authentic contexts.

\section{B- Speaking}

1-Speak English words and sentences clearly, and fluently in a variety of academic authentic contexts.

2- Use words and sentences to participate in discussions and conversations in a variety of academic authentic contexts

3- Take part in a variety of well- prepared presentations to the class in a variety of academic authentic contexts.

\section{C-Reading}

1- Use reading strategies to understand a variety of authentic informational and literary texts.

2- Demonstrate understanding of a variety of authentic informational and literary texts (e.g., applications, social and scientific reports, academic essays, plays, and poems)

3- Make connections between prior knowledge and experiences and a variety of authentic informational and literary texts ( e.g., applications, social and scientific reports, academic essays, plays, and poems).

\section{D-Writing}

1- Gather information and ideas from print and electronic sources to organize and write in a variety of advanced authentic contexts.

2- Write a series of paragraphs for a variety of advanced authentic purposes and audiences such as summaries, essays, resumes, and multi-media presentations.

3- Use appropriate organizational patterns to create authentic advanced written work.

4- Apply knowledge of the conventions of language (e,g., spelling, punctuation, grammar, and usage)

5- Revise written work for accuracy, clarity, correctness and coherence with the assistance of teacher, peers, and electronic programs. 
Herman (1997) said that: teachers model that classroom practices online with the methods and the result of the various assessments that they employed and that assessment influences classroom teaching and student activities.

Jordan Opportunities aims at reinforcing English acquired during the Basic Education Stage as well as providing learners with new language experiences that can be used in a variety of relevant situations. The Ministry of Education allotted four 45-minute periods per week. All second secondary stage students in all streams must pass the GSCE (General Secondary Certificate Examination) by getting at least 35 out of 70 in each of the two sessions of the twelfth grade.

Language testing has traditionally been limited by considerations of validity (whether tests actually measure what they are supposed to measure [Thrasher, 1984]), reliability (whether they produce similar results on more than one occasion) and efficiency (logistics of test administration), (Weir 1988:1). Validity is seen by Spolsky (1975) and Messick (1988) as the major problem in foreign language testing, including content validity (the test is a representative sample of the language skills and structures it is meant to test), criterion-related validity, construct-validity (the extent to which the test matches a theoretical construct), (Bachman 1990), face-validity (the test looks reasonable to the test-taker), predictive validity (the predictive force of the test), concurrent-validity (the test and the criterion are administered at the same time), (Davies 1990), and educational validity (the relationship between positive test effects and students study habits), (Thrasher 1984). Nakamura (1995) argued that predictive validity, educational validity, construct validity, concurrent validity, face validity and content validity should be analyzed in tests of speaking ability, and Kohonen (1999:291) stresses also validity in communicative evaluation.

Claire (2000) gave some reminders about assessment:

-assessment instruments should measure expected outcomes.

- expected outcomes need to be clear to student and teacher.

- no one instrument captures everything ; use more than one.

- external review is an appropriate complement to internal assessment.

- demonstrating learning over time is ideal.

- results need to be shared, acted upon and re-measured close the loop.

\section{Literature Review}

Specialist get confused when they hear the words assessment, evaluation and testing. Hart (1994) has given a helpful explanation of these terms. He says assessment refers to the methods we use to find out what students are learning. Brown (1994) stated that people get tested every day in different situations where they have to make decisions.

Harrison et al (1975:4) surveyed the Jordanian state of English system. They indicated, "The final English language attainment of each school graduate is evaluated by his success or failure in the GSCE in English. The form of this required examination obviously affects the manner and the substance of English language teaching. Typically, the examination does not assess pupils' spontaneous oral production or their listening comprehension, but it does attempt to measure their ability to demonstrate a knowledge of formal grammatical relationships and their ability to comprehend written passages."

They added "It must be assumed that the lack of correspondence between the specific objectives in the new curriculum guide and the present examination system will yield a teaching program oriented to prepare students to pass the required examination. This orientation does not, of course, preclude the possibility that students who pass the examination can also communicate effectively and confidently using the four basic skills."

Hamdan (1992) conducted a study to measure the students' competence against the "general objectives" of Basic Stage English Curriculum in Jordan. The subjects selected for his study were 70 tenth-grade students, of which were 35 male students, and 35 female students. Hamdan employed a test to measure the students' competence in the following sub-scales: listening, speaking, reading, writing, vocabulary and structures. The results of his study indicated that:

(1) All the subjects scored successfully on the whole test.

(2) The female group was ahead in respect to the whole test mean scores.

(3) There were no statistically significant differences in the achievement of male and female subjects on the receptive skills and productive skills. 
There were no statistically significant differences among the male subjects on productive and receptive skills.

There were statistically significant differences among the female subjects on productive and receptive skills.

In the light of his findings, Hamdan recommended that efforts should be geared towards developing general proficiency examinations reflecting the teaching approaches and the attainment of the test objectives. Consequently, training courses should be held for teachers of English so as to make them aware of developing evaluation strategies of instructional objectives.

Al-Belushi (1997) conducted a study to investigate factors that might explain why third secondary arts students in the Sultanate of Oman performed less well than science students on the English Language National Certificate Examinations. Her study sought to determine whether there were relationships among student performance, major, gender, educational and family background, and relevant pedagogical attitudes and perceptions. Both quantitative and qualitative methods were used. Third secondary subjects included (992) arts and science students and (34) teachers. Students completed a self-administered questionnaire and teachers were interviewed. Several striking results emerged from the study. First, although science students performed better on the English examination, they did not perform as well on the overall examinations as did the arts students. Second, science students and teachers of both arts and science students generally held negative attitudes toward arts students, but positive attitudes toward science students (attitudes which seem to mirror those of Omani society in general). Third, both arts and science students faced difficulties in learning the English language.

Bani Abdelrahamn (2003) conducted a study to investigate the General Secondary Certificate Examination in Jordan (GSCE) through: assessing the extent to which English Language Teaching Objectives are realized in the GSCE in Jordan between 1997 and 2002 and to develop a guide for the writers of the GSCE in English. The sample of the study consists of all examination papers of the GSCE in English in Jordan between the years 1997 and 2002. For the purpose of the study, the researcher developed a questionnaire that consists of 46 Thirston -type items that were classified under the following categories:

1- $\quad$ Listening and speaking, 5 items.

2- Reading, 10 items.

3- Writing, 10 items.

4- Functions, 21 items.

The study presents the following findings:

1- The objectives of listening and speaking are not available in the GSCE completely.

2 - $\quad 50 \%$ of the reading objectives are available in the GSCE.

3- $\quad 40 \%$ of the writing objectives are available in the GSCE .

$4-\quad 24 \%$ of the functions are available in the GSCE.

Bani Abdelrahman (2009) conducted a study to find out to what extent do EFL students achieve every goal (description, inferences, what does each person like, excuses, requests, offers and apologies) separately and to what extent do students achieve all the goals collectively. The population and sample of the study consisted of all the students who studied at elementary level at the I.P.A in Riyadh in Saudi Arabia in the first semester 2007. In order to answer the questions of the study, the researcher prepared an exam that contained of 29 multiple-choice questions. The findings of the study showed that the description, inferences and what each person likes were achieved by the students to a good level while excuses, requests, offers and apologies were not achieved by the students. As a whole the level of achievement was a good one for the exam as a whole.

The present study reinforces the same ideas and shares with these studies an interest about the students' previous knowledge. As such, considering the objectives before writing the examination is necessary and useful to achieve better results in learning.

\section{Population and sample}

The population and sample of the study consisted of all the examination papers of GSCE in English in Jordan between the years 2008 and 2010 . 


\section{Instrument of the Study}

Data were collected through using a questionnaire for the subject of the study. The scale contained 13 Thirston-type items. The 13 Thirston-type items were classified under the following categories:

1-listening 2

2- speaking 3

3- reading 3

4 - writing 5

The questionnaire was prepared in English. The questionnaire was given to a jury of professors, supervisors and teachers of English. The researcher, through revising the literature, developed the questionnaire into two columns "available" and "unavailable", as there is no other choice for seeing whether the objective is available or not. So, in giving the data to the computer "available" is represented by number 1 while" unavailable" is represented by number 2.

\section{Data Analysis}

The subjects' responses to the questionnaire were analyzed as follows:

1- $\quad$ Percentage and frequency in each response category.

2- $\quad$ Basic descriptive statistical mean and standard deviation.

\section{Validity and Reliability of the Instrument}

In order to establish its validity, the researcher gave the questionnaire to a jury of specialized TEFL experts (4 teachers, 3 supervisors, 5 professors) for their comments and recommendations.

The jury agreed that the instrument is valid to measure what it is supposed to measure. The researcher used the Inter-rater Reliability Agreement to find the reliability coefficient for the questionnaire as a unit for the whole sample. It was calculated based on the generalizability theory, and it was (0.99).

$$
\begin{aligned}
\mathrm{P}^{2} & =\frac{\text { Msp }- \text { Msr }}{\text { Msp }} \\
& =\frac{18.195-0.064}{18.195} \\
& =\frac{18.131}{18.195} \\
& =0,99
\end{aligned}
$$

\section{Administration of the Questionnaire}

The researcher distributed the questionnaire to the EFL teachers, supervisors and professors personally. The researcher explained the items of all the scale to the subjects and answered all the questions they raised. The subjects consisted of 10 professors, 12 supervisors and 8 teachers.

\section{Statement of the problem}

Students of the GSCE complain that they are not tested in what they should study at schools in English because the objectives of the English language curricula are not reflected in the test. This study aimed to analyze the GSCE questions and see the availability of the English Language Objectives in them.

So, the study aimed to answer the following questions:

3- To what extent are the English language Teaching objectives realized in the GSCE in Jordan between 2008 and 2010 for each academic year? 
4- To what extent are the English language Teaching objectives realized in the GSCE in Jordan between 2008 and 2010 for all the three years collectively?

\section{Purpose of the Study}

The study aimed at investigating the GSCE through assessing to what extent English Language Teaching Objectives are available in the GSCE in Jordan between 2008 and 2010.

\section{Significance of the Study}

The Ministry of Education in Jordan introduced Jordan Opportunities series in 2008. Every year, the Ministry of Education carries out an examination in English. The first general examination about 'Jordan Opportunities' was administered in 2008 as it was the first year when Jordan Opportunities series was used.

To the knowledge of the researcher, there haven't been any studies done to find out the availability of the objectives in the GSCE in Jordan except the one that Bani Abdelrahaman (2003) conducted. So, a study of analyzing the second secondary examination in English will

1- $\quad$ supply the examination writers with objective and useful information for writing questions,

2- contribute to the development of any similar future examination,

3- measure the extent to which the Ministry of Education realizes the objectives of teaching English language in Jordan, and

4- supply recommendations in light of the findings of the study.

\section{Definition of Terms}

Basic Education Stage: Consists of grades one to ten, in Jordan.

English Language Teaching Objectives: are explained in detail in the preface of this dissertation.

GSCE: General Secondary Certificate Examination in Jordan which is carried out at the end of the secondary stage.

Jordan Opportunities: a series of textbooks which is taught at the Secondary Stage and the highest class of the Basic Education Stage, grades 10, 11 and 12 in Jordan.

Secondary Education Stage: Consists of the highest two grades in Jordanian schools: grades eleven and twelve.

\section{Discussion of the Results}

\subsection{Subjects' responses to the questionnaire of the four subscales for the year 2008.}

\section{A) Listening}

The listening subscale consisted of two items. Frequencies, percentages, means and standard deviations of the responses to each item are presented in Table 1.

Table 1 shows that all the categories include complete percentages in the "unavailable" column. The mean of the two items (1- Develop advanced listening strategies in academic and authentic contexts.... 2Demonstrate understanding of directions, presentations and performances in a variety of authentic contexts.. was too high. This means that listening was not available in the GSCE.

\section{B) Speaking}

The speaking subscale consisted of three items. Frequencies, percentages, means and standard deviations of the responses to each item are presented in Table 2.

Table 2 shows that all the categories include complete percentages in the "unavailable" column. The mean of the three items (1- Speak English words and sentences clearly, and fluently in a variety of academic authentic contexts.... 2- Use words and sentences to participate in discussions and conversations in a variety of academic authentic contexts. 3 -Take part in a variety of well- prepared presentations to the class in a variety of academic authentic contexts.. was too high. This means that speaking was not available in the GSCE.

\section{C) Reading}

The reading subscale consisted of three items. Frequencies, Percentages, Means and Standard Deviations of the responses to each item are presented in Table 3.

Table 3 shows that item (1- Use reading strategies to understand a variety of authentic informational and literary texts) and item (2-Demonstrate understanding of a variety of authentic informational and literary texts (e.g., applications, social and scientific reports, academic essays, plays, and poems) include high percentage in the 
available column. While item (3-Make connections between prior knowledge and experiences and a variety of authentic informational and literary texts (e.g., applications, social and scientific reports, academic essays, plays, and poems) includes acceptable percentage in the available column.

\section{D) Writing}

The writing subscale consisted of five items. Frequencies, percentages, means and standard deviations of the responses to each item are presented in Table 4.

As seen from this table4, items 2,3,4, and 5 (2- Write a series of paragraphs for a variety of advanced authentic purposes and audiences such as summaries, essays, resumes, and multi-media presentations 3- Use appropriate organizational patterns to create authentic advanced written work. 4- Apply knowledge of the conventions of language (e,g., spelling, punctuation, grammar, and usage) 5- Revise written work for accuracy, clarity, correctness and coherence with the assistance of teacher, peers, and electronic programs.) include very high percentage in the available column while item 1 (Gather information and ideas from print and electronic sources to organize and write in a variety of advanced authentic contexts.) includes high percentage in the available column which means that item 1 was not available in the GSCE.

12.2 Subjects' responses to the questionnaire of the four subscales for the year 2009.

\section{A) Listening}

The listening subscale consisted of two items. Frequencies, percentages, means and standard deviations of the responses to each item are presented in Table 5.

Table 5 shows that all the two items include complete percentages in the "unavailable" column. This means that listening was not available in the GSCE.

\section{B) Speaking}

The speaking subscale consisted of three items. Frequencies, percentages, means and standard deviations of the responses to each item are presented in Table 6.

Table 6 shows that all the categories include complete percentages in the "unavailable" column. This means that speaking was not available in the GSCE.

\section{C) Reading}

The reading subscale consisted of three items. Frequencies, Percentages, Means and Standard Deviations of the responses to each item are presented in Table 7.

Table 7 shows that the three items include very high percentages in the available column. These items were used in the GSCE.

\section{D) Writing}

The writing subscale consisted of five items. Frequencies, percentages, means and standard deviations of the responses to each item are presented in Table 8 .

As seen from this table, items 2, 3, 4, and 5 include very high percentages in available column. That means they were available in GSCE. But item 1 includes low percentage in the available column which means that it was not completely used in GSCE.

12.3 Subjects' responses to the questionnaire of the four subscales for the year 2010.

\section{A) Listening}

The listening subscale consisted of two items. Frequencies, percentages, means and standard deviations of the responses to each item are presented in Table 9.

Table 9 shows that all the categories include complete percentages in the "unavailable" column. This means that listening was not available in the GSCE.

\section{B) Speaking}

The speaking subscale consisted of three items. Frequencies, percentages, means and standard deviations of the responses to each item are presented in Table 10.

Table 10 shows that all the categories include complete percentages in the "unavailable" column. This means that speaking was not available in the GSCE. 


\section{C) Reading}

The reading subscale consisted of three items. Frequencies, Percentages, Means and Standard Deviations of the responses to each item are presented in Table 11.

Table 11 shows that items 1 and 2 include very high percentages in available column. That means that they were used in the GSCE. While item 3 includes low percentage in the available column which means it was not completely used.

\section{D) Writing}

The writing subscale consisted of five items. Frequencies, percentages, means and standard deviations of the responses to each item are presented in Table 12.

As seen from this table, items 2, 3, 4, and 5 include very high percentages in available column . That means they were available in GSCE. But item 1 includes low percentage in the available column which means that it was not completely used in GSCE.

12.4 Subjects' responses to the questionnaire of the four subscales from the year 2008 to 2010 (Three years together).

\section{A) Listening}

The listening subscale consisted of two items. Frequencies, percentages, means and standard deviations of the responses to each item are presented in Table 13. Availability of the items in the GSCE between the years 2008 and 2010 is presented in Table 14.

As seen from Tables 13 and 14 all the categories include complete percentages in the unavailable column. This means that listening was "unavailable" in the GSCE over the three years.

\section{B) Speaking}

The speaking subscale consisted of three items. Frequencies, percentages, means and standard deviations of the responses to each item are presented in Table 15. Availability of the items in the GSCE between the years 2008 and 2010 is presented in Table 16.

As seen from Tables 15 and 16, all the categories include complete percentages in the unavailable column. This means that speaking was "unavailable" in the GSCE over the three years.

\section{C) Reading}

The reading subscale consisted of three items. Frequencies, percentages, means and standard deviations of the responses to each item are presented in Table 17. Availability of the items in the GSCE between the years 2008and 2010 is presented in Table 18.

As seen from Tables 17 and 18 that items 1 and 2 include very high percentages in the available column. This means that they were "available" in the GSCE over the three years. By contrast item 3 includes half of the percentage that means it was not always available.

\section{D) Writing}

The writing subscale consisted of five items. Frequencies, percentages, means and standard deviations of the responses to each item are presented in Table 19. Availability of the items in the GSCE between 2008 and 2010 is presented in table 20 .

As seen from Tables 19 and 20, items 2, 3, 4, and 5 include very high percentages in available column .That means they were available in GSCE over the three years. But item 1 includes low percentage in the available column which means that it was not always used or available in GSCE over the three years.

\section{Findings of the Study}

The findings of the study support the researcher hypothesized before conducting this study that the objectives of listening and speaking are not available in the GSCE.

Concerning the reading objectives, it is found out that the first and second objectives were available but the third one was not to a large extent. While writing objectives $2,3,4$, and 5 were available but the first objective was not available to an acceptable level.

The study presents the following

4- The objectives of listening and speaking are not available in the GSCE completely. 
5- Two out of three of the reading objectives are available.

6- Four out of five of the writing objectives are available in the GSCE.

On the basis of the findings, the researcher recommended the following:

4- Include speaking and listening exams in the GSCE because of the need to let teachers teach them in classes.

5- Vary the questions of reading and writing to cover all the objectives.

6- To test what we teach not to teach what we are going to test as the case in most schools.

\section{References}

Al-Belushi, S. (1997). An Examination of the Reasons Science students Outperform Arts Students in the English Language National Certificate Examination in the Sultanate of Oman. Unpublished Ph.D Dissertation. University of Louisvelle, Louisville, Kentucky School of Education.

Bachman, L. (1990). Fundamental Considerations in Language Testing. Oxford: Oxford University Press.

Bani Abdelrahman, M. (2003). The Realization of the English Language Teaching Objectives in the General Secondary Certificate Examination Questions in Jordan Between 1997 and 2002: Towards Developing Improvement Guidelines. Unpublished Doctoral Dissertation, Amman Arab University, Amman, Jordan.

Bani Abdelrahman, M. (2009). The Degree of Achieving the Goals of Using "BASIC English Skills" by the Elementary Level Students in the Institute of Public Administration. Journal of Education and Psychology, No. 33 (2). Ain Shams University, Cairo, Egypt.

Brown, H.Douglas. (1994). Principles of Language Learning and Teaching. Third Edition, Prentice Hall Regent, England Cliffs, N.J.

Claire, S. (2000). Assessment of Student Learning: An Introduction. Western New England College. [Online] available: www.wnec.edu.

Davies, A. (1990). Principles of Language Testing. Oxford: Basil Blackwell.

Hamdan,M. H. (1992). Measuring the Students' Competence Against the General Objectives of Basic Stage English Curriculum in Jordan. Unpublished M. Ed, Thesis. Yarmouk University, Irbid. Jordan.

Harrison, William.et al. (1975). English Language Policy Survey of Jordan. Center for Applied Linguistics, U.S.A.

Hart, D. (1994). Authentic Assessment. Menlo Parl, CA: Addison-Wesley Publishing Company.

Herman, J. (1997). Assessing new assessments: how do they measure up? Theory into practice, 36(4), 196-204.

Kohonen, V. (1999). Authentic assessment in affective foreign language education. In J. Arnold, (Ed.). Affect in Language Learning. Cambridge: Cambridge University Press, 279-94.

Messick, S. (1988). The once and future issues of validity: Assessing the meaning and consequences of measurement. In H. Wainer, \& H.I. Braun, (Eds.). Test Validity.

Ministry of Education. (2008). English Language General Guidelines and Curricula for the Secondary Education Stage Comprehensive and Applied.

Ministry of Education. (2008). Jordan Opportunities 3 Twelfth Grade student's book. Second Secondary Class. All streams.

Ministry of Education. (2008). Jordan Opportunities 3 Twelfth Grade Teacher's book. Second Secondary Class. All streams.

Ministry of Education. (2008). Jordan Opportunities 3 Twelfth Grade Workbook. Second Secondary Class. All streams.

Nakamura, Y. (1995). Making speaking tests valid: Practical considerations in a classroom setting. In J. D.Brown, \& S.O. Yamashita (Eds.). Language Testing in Japan. Tokyo, Japan: The Japan Association for Language Teaching, 126-135.

Spolsky, B. (1975). Language testing - the problem of validation. In L. Palmer \& B. Spolsky (Eds.). Papers on language testing 1967-1974. Washington, D.FC.: TESOL. 147-53.

Thrasher, R.H. (1984). Educational validity. Annual reports, International Christian University, 9, 67-84.

Weir, C.J. (revised edition, 1998). Communicative Language Testing. Exeter: University of Exeter Press. 
Table 1. Frequencies, Percentages, Means and Standard Deviations (SD) of the Subjects' Responses on the Listening Subscale

\begin{tabular}{|c|c|c|c|c|c|c|}
\hline \multirow{2}{*}{ Item } & \multicolumn{2}{|c|}{ Available } & \multicolumn{2}{c|}{ Unavailable } & \multirow{2}{*}{ Mean } & SD \\
\cline { 2 - 5 } & No. & $\%$ & No. & $\%$ & & \\
\hline 1 & 0 & 0 & 30 & 100 & 2 & 0 \\
\hline 2 & 0 & 0 & 30 & 100 & 2 & 0 \\
\hline
\end{tabular}

Table 2. Frequencies, Percentages, Means and Standard Deviations (SD) of the Subjects' Responses on the Speaking Subscale

\begin{tabular}{|c|c|c|c|c|c|c|}
\hline \multirow{2}{*}{ Item } & \multicolumn{2}{|c|}{ Available } & \multicolumn{2}{c|}{ Unavailable } & \multirow{2}{*}{ Mean } & \multirow{2}{*}{ SD } \\
\cline { 2 - 5 } & No. & $\%$ & No. & $\%$ & & \\
\hline 1 & 0 & 0 & 30 & 100 & 2 & 0 \\
\hline 2 & 0 & 0 & 30 & 100 & 2 & 0 \\
\hline 3 & 0 & 0 & 30 & 100 & 2 & 0 \\
\hline
\end{tabular}

Table 3. Frequencies, Percentages, Means and Standard Deviations (SD) of the Subjects' Responses on the Reading Subscale

\begin{tabular}{|c|c|c|c|c|c|c|}
\hline \multirow[t]{2}{*}{ Item } & \multicolumn{2}{|c|}{ Available } & \multicolumn{2}{|c|}{ Unavailable } & \multirow[t]{2}{*}{ Mean } & \multirow[t]{2}{*}{$\mathrm{SD}$} \\
\hline & No & $\%$ & No & $\%$ & & \\
\hline 1 & 27 & 90 & 3 & 10 & 1.10 & .30 \\
\hline 2 & 27 & 90 & 3 & 10 & 1.10 & .30 \\
\hline 3 & 18 & 60 & 12 & 40 & 1.40 & .49 \\
\hline
\end{tabular}

Table 4. Frequencies, Percentages, Means and Standard Deviations (SD) of the Subjects' Responses on the Writing Subscale

\begin{tabular}{|c|c|c|c|c|c|c|}
\hline \multirow{2}{*}{ Item } & \multicolumn{2}{|c|}{ Available } & \multicolumn{2}{c|}{ Unavailable } & Mean & SD \\
\cline { 2 - 5 } & No & $\%$ & No & $\%$ & & \\
\hline 1 & 9 & 30 & 21 & 70 & 1.70 & .46 \\
\hline 2 & 28 & 93.3 & 2 & 6.7 & 1.06 & .25 \\
\hline 3 & 28 & 93.3 & 2 & 6.7 & 1.06 & .25 \\
\hline 4 & 29 & 96.7 & 1 & 3.3 & 1.03 & .18 \\
\hline 5 & 28 & 93.3 & 2 & 6.7 & 1.06 & .25 \\
\hline
\end{tabular}

Table 5. Frequencies, Percentages, Means and Standard Deviations (SD) of the Subjects' Responses on the Listening Subscale

\begin{tabular}{|c|c|c|c|c|c|c|}
\hline \multirow{2}{*}{ Item } & \multicolumn{2}{|c|}{ Available } & \multicolumn{2}{c|}{ Unavailable } & \multirow{2}{*}{ Mean } & SD \\
\cline { 2 - 5 } & No. & $\%$ & No. & $\%$ & & 2 \\
\hline 1 & 0 & 0 & 30 & 100 & 2 & 0 \\
\hline 2 & 0 & 0 & 30 & 100 & 2 & 0 \\
\hline
\end{tabular}


Table 6. Frequencies, Percentages, Means and Standard Deviations (SD) of the Subjects' Responses on the Speaking Subscale

\begin{tabular}{|c|c|c|c|c|c|c|}
\hline \multirow{2}{*}{ Item } & \multicolumn{2}{|c|}{ Available } & \multicolumn{2}{c|}{ Unavailable } & \multirow{2}{*}{ Mean } & \\
\cline { 2 - 6 } & No. & $\%$ & No. & $\%$ & & 0 \\
\hline 1 & 0 & 0 & 30 & 100 & 2 & 0 \\
\hline 2 & 0 & 0 & 30 & 100 & 2 & 0 \\
\hline 3 & 0 & 0 & 30 & 100 & 2 & 0 \\
\hline
\end{tabular}

Table 7. Frequencies, Percentages, Means and Standard Deviations (SD) of the Subjects' Responses on the Reading Subscale

\begin{tabular}{|c|c|c|c|c|c|c|}
\hline \multirow{2}{*}{ Item } & \multicolumn{2}{|c|}{ Available } & \multicolumn{2}{c|}{ Unavailable } & \multirow{2}{*}{ Mean } & \multirow{2}{*}{ SD } \\
\cline { 2 - 6 } & No & $\%$ & No & $\%$ & & .25 \\
\hline 1 & 28 & 93.3 & 2 & 6.7 & 1.06 & .18 \\
\hline 2 & 29 & 96.7 & 1 & 3.3 & 1.03 & .47 \\
\hline 3 & 20 & 66.7 & 10 & 33.3 & 1.33 & \\
\hline
\end{tabular}

Table 8. Frequencies, Percentages, Means and Standard Deviations (SD) of the Subjects' Responses on the Writing Subscale

\begin{tabular}{|c|c|c|c|c|c|c|}
\hline \multirow{2}{*}{ Item } & \multicolumn{3}{|c|}{ Available } & \multicolumn{2}{c|}{ Unavailable } & \multirow{2}{*}{ Mean } \\
\cline { 2 - 6 } & No & $\%$ & No & $\%$ & & \\
\hline 1 & 11 & 36.7 & 19 & 63.3 & 1.63 & .49 \\
\hline 2 & 27 & 90 & 3 & 10 & 1.10 & .30 \\
\hline 3 & 28 & 93.3 & 2 & 6.7 & 1.06 & .25 \\
\hline 4 & 28 & 93.3 & 2 & 6.7 & 1.06 & .25 \\
\hline 5 & 30 & 100 & 0 & .00 & 1.00 & .00 \\
\hline
\end{tabular}

Table 9. Frequencies, Percentages, Means and Standard Deviations (SD) of the Subjects' Responses on the Listening Subscale

\begin{tabular}{|c|c|c|c|c|c|c|}
\hline \multirow{2}{*}{ Item } & \multicolumn{2}{|c|}{ Available } & \multicolumn{2}{c|}{ Unavailable } & \multirow{2}{*}{ Mean } & \\
\cline { 2 - 5 } & No. & $\%$ & No. & $\%$ & & 0 \\
\hline 1 & 0 & 0 & 30 & 100 & 2 & 0 \\
\hline 2 & 0 & 0 & 30 & 100 & 2 & 0 \\
\hline
\end{tabular}

Table 10. Frequencies, Percentages, Means and Standard Deviations (SD) of the Subjects' Responses on the Speaking Subscale

\begin{tabular}{|c|c|c|c|c|c|c|}
\hline \multirow[t]{2}{*}{ Item } & \multicolumn{2}{|c|}{ Available } & \multicolumn{2}{|c|}{ Unavailable } & \multirow[t]{2}{*}{ Mean } & \multirow[t]{2}{*}{$\mathrm{SD}$} \\
\hline & No. & $\%$ & No. & $\%$ & & \\
\hline 1 & 0 & 0 & 30 & 100 & 2 & 0 \\
\hline 2 & 0 & 0 & 30 & 100 & 2 & 0 \\
\hline 3 & 0 & 0 & 30 & 100 & 2 & 0 \\
\hline
\end{tabular}


Table 11. Frequencies, Percentages, Means and Standard Deviations (SD) of the Subjects' Responses on the Reading Subscale

\begin{tabular}{|c|c|c|c|c|c|c|}
\hline \multirow{2}{*}{ Item } & \multicolumn{2}{|c|}{ Available } & \multicolumn{2}{c|}{ Unavailable } & \multirow{2}{*}{ Mean } & \\
\cline { 2 - 5 } & No & $\%$ & No & $\%$ & & \\
\hline 1 & 29 & 96.7 & 1 & 3.3 & 1.03 & .18 \\
\hline 2 & 29 & 96.7 & 1 & 3.3 & 1.03 & .18 \\
\hline 3 & 11 & 36.7 & 19 & 63.3 & 1.63 & .49 \\
\hline
\end{tabular}

Table 12. Frequencies, Percentages, Means and Standard Deviations (SD) of the Subjects' Responses on the Writing Subscale

\begin{tabular}{|c|c|c|c|c|c|c|}
\hline \multirow{2}{*}{ Item } & \multicolumn{2}{|c|}{ Available } & \multicolumn{2}{c|}{ Unavailable } & \multirow{2}{*}{ Mean } & \multirow{2}{*}{ SD } \\
\cline { 2 - 6 } & No & $\%$ & No & $\%$ & & .50 \\
\hline 1 & 13 & 43.3 & 17 & 56.7 & 1.56 & .25 \\
\hline 2 & 28 & 93.3 & 2 & 6.7 & 1.06 & .25 \\
\hline 3 & 28 & 93.3 & 2 & 6.7 & 1.06 & .25 \\
\hline 4 & 28 & 93.3 & 2 & 6.7 & 1.06 & .25 \\
\hline 5 & 28 & 93.3 & 2 & 6.7 & 1.06 & .06 \\
\hline
\end{tabular}

Table 13. Frequencies, Percentages, Means and Standard Deviations (SD) of the Subjects' Responses on the Listening Subscale

\begin{tabular}{|c|c|c|c|c|c|c|}
\hline \multirow[t]{2}{*}{ Item } & \multicolumn{2}{|c|}{ Available } & \multicolumn{2}{|c|}{ Unavailable } & \multirow[t]{2}{*}{ Mean } & \multirow[t]{2}{*}{ SD } \\
\hline & No & $\%$ & No & $\%$ & & \\
\hline 1 & 0 & 0 & 90 & 100 & 2 & 0 \\
\hline 2 & 0 & 0 & 90 & 100 & 2 & 0 \\
\hline Total & 0 & 0 & 180 & 100 & 2 & 0 \\
\hline
\end{tabular}

Table 14. Availability of the Listening Subscale items in the GSCE between the years 2008 and 2010

\begin{tabular}{|c|c|c|c|c|c|c|c|c|}
\hline \multirow{2}{*}{ Item } & \multicolumn{2}{|c|}{2008} & \multicolumn{2}{c|}{2009} & \multicolumn{2}{c|}{2010} & \multicolumn{2}{c|}{ Total } \\
\cline { 2 - 9 } & Av & Un & Av & Un & Av & Un & Av & Un \\
\hline 1 & & $\sqrt{ }$ & & $\sqrt{ }$ & & $\sqrt{ }$ & & 3 \\
\hline 2 & & $\sqrt{ }$ & & $\sqrt{ }$ & & $\sqrt{ }$ & & 3 \\
\hline Total & 0 & 2 & 0 & 2 & 0 & 2 & 0 & 6 \\
\hline
\end{tabular}

Table 15. Frequencies, Percentages, Means and Standard Deviations (SD) of the Subjects' Responses on the Speaking Subscale

\begin{tabular}{|c|c|c|c|c|c|c|}
\hline \multirow[t]{2}{*}{ Item } & \multicolumn{2}{|c|}{ Available } & \multicolumn{2}{|c|}{ Unavailable } & \multirow[t]{2}{*}{ Mean } & \multirow[t]{2}{*}{$\mathrm{SD}$} \\
\hline & No & $\%$ & No & $\%$ & & \\
\hline 1 & 0 & 0 & 90 & 100 & 2 & 0 \\
\hline 2 & 0 & 0 & 90 & 100 & 2 & 0 \\
\hline 3 & 0 & 0 & 90 & 100 & 2 & 0 \\
\hline Total & 0 & 0 & 270 & 100 & 2 & 0 \\
\hline
\end{tabular}


Table 16. Availability of the Speaking Subscale items in the GSCE between the years 2008 and 2010

\begin{tabular}{|c|c|c|c|c|c|c|c|c|}
\hline \multirow{2}{*}{ Item } & \multicolumn{2}{|c|}{2008} & \multicolumn{2}{c|}{2009} & \multicolumn{2}{c|}{2010} & \multicolumn{2}{c|}{ Total } \\
\cline { 2 - 9 } & Av & Un & Av & Un & Av & Un & Av & Un \\
\hline 1 & & $\sqrt{ }$ & & $\sqrt{ }$ & & $\sqrt{ }$ & & 3 \\
\hline 2 & & $\sqrt{ }$ & & $\sqrt{ }$ & & $\sqrt{ }$ & & 3 \\
\hline 3 & & $\sqrt{ }$ & & $\sqrt{ }$ & & $\sqrt{ }$ & & 3 \\
\hline Total & 0 & 3 & 0 & 3 & 0 & 3 & 0 & 9 \\
\hline
\end{tabular}

Table 17. Frequencies, Percentages, Means and Standard Deviations (SD) of the Subjects' Responses on the Reading Subscale

\begin{tabular}{|c|c|c|c|c|c|c|}
\hline \multirow{2}{*}{ Item } & \multicolumn{2}{|c|}{ Available } & \multicolumn{2}{c|}{ Unavailable } & \multirow{2}{*}{ Mean } & \multirow{2}{*}{ SD } \\
\cline { 2 - 6 } & No & $\%$ & No & $\%$ & & .25 \\
\hline 1 & 84 & 93.3 & 6 & 6.7 & 1.06 & .23 \\
\hline 2 & 85 & 94.4 & 5 & 5.6 & 1.05 & .50 \\
\hline 3 & 49 & 54.4 & 41 & 45.6 & 1.45 & 2010 \\
\hline
\end{tabular}

Table 18. Availability of the Reading Subscale Items in the GSCE Between the Years 2008 and 2010

\begin{tabular}{|c|c|c|c|c|c|c|c|c|}
\hline \multirow{2}{*}{ Item } & \multicolumn{2}{|c|}{2008} & \multicolumn{2}{c|}{2009} & \multicolumn{2}{c|}{2010} & \multicolumn{2}{c|}{ Total } \\
\cline { 2 - 10 } & Av & Un & Av & Un & Av & Un & Av & Un \\
\hline 1 & $\sqrt{ }$ & & $\sqrt{ }$ & & $\sqrt{ }$ & & 3 & \\
\hline 2 & $\sqrt{ }$ & & $\sqrt{ }$ & & $\sqrt{ }$ & & 3 & \\
\hline 3 & & $\sqrt{ }$ & & $\sqrt{ }$ & & $\sqrt{ }$ & & 3 \\
\hline Total & 2 & 1 & 2 & 1 & 2 & 1 & 6 & 3 \\
\hline
\end{tabular}

Table 19. Frequencies, Percentages, Means and Standard Deviations (SD) of the Subjects' Responses on the Writing Subscale

\begin{tabular}{|c|c|c|c|c|c|c|}
\hline \multirow[t]{2}{*}{ Item } & \multicolumn{2}{|c|}{ Available } & \multicolumn{2}{|c|}{ Unavailable } & \multirow[t]{2}{*}{ Mean } & \multirow[t]{2}{*}{$\mathrm{SD}$} \\
\hline & No & $\%$ & No & $\%$ & & \\
\hline 1 & 33 & 36.7 & 57 & 63.3 & 1.63 & .48 \\
\hline 2 & 83 & 92.2 & 7 & 7.8 & 1.07 & .26 \\
\hline 3 & 84 & 93.3 & 6 & 6.7 & 1.06 & .25 \\
\hline 4 & 85 & 94.4 & 5 & 5.6 & 1.05 & .23 \\
\hline 5 & 86 & 95.6 & 4 & 4.4 & 1.04 & .20 \\
\hline
\end{tabular}

Table 20. Availability of the Writing Subscale Items in the GSCE Between the Years 2008 and 2010

\begin{tabular}{|c|c|c|c|c|c|c|c|c|}
\hline \multirow{2}{*}{ Item } & \multicolumn{2}{|c|}{2008} & \multicolumn{2}{c|}{2009} & \multicolumn{2}{c|}{2010} & \multicolumn{2}{c|}{ Total } \\
\cline { 2 - 10 } & Av & Un & Av & Un & Av & Un & Av & Un \\
\hline 1 & & $\sqrt{ }$ & & $\sqrt{ }$ & & $\sqrt{ }$ & & 3 \\
\hline 2 & $\sqrt{ }$ & & $\sqrt{ }$ & & $\sqrt{ }$ & & 3 & \\
\hline 3 & $\sqrt{ }$ & & $\sqrt{ }$ & & $\sqrt{ }$ & & 3 & \\
\hline 4 & $\sqrt{ }$ & & $\sqrt{ }$ & & $\sqrt{ }$ & & 3 & \\
\hline 5 & $\sqrt{ }$ & & $\sqrt{ }$ & & $\sqrt{ }$ & & 3 & \\
\hline Total & 4 & 1 & 4 & 1 & 4 & 1 & 12 & 3 \\
\hline
\end{tabular}


The Hashimate Kingdom of Jordan

Al-Hussain Bin Talal University

Faculty of Educational Studies

Curriculum and Instruction Department

\section{A Questionnaire}

An Analysis of "Jordan Opportunities" Objectives in the General Secondary Certificate Examination of English: A Case Study in Jordan between 2008 and 2010

Dear

This study is conducted to identify the extent to which English Language Teaching Objectives are available in the General Secondary Certificate Examination Questions in Jordan between the years 2008 and 2010.

As a specialist, you are kindly invited to analyze the examination questions attached to this questionnaire.

Please put a (v) in the column that best describes your evaluation of the statement in the questionnaire (e.g. available, unavailable).

I would thankfully receive your recommendations in this regard to best serve academic research.

Your cooperation is highly appreciated.

Dr. Mahmoud Sulaiman Bani Abdel-Rahman 


\section{A Questionnaire for the University staff, Supervisors and Teachers of English}

Name:

Place of work:

Job:

Years of experience:

Qualifications:

Please put a (v) in the column that best describes your evaluation of the following statements about whether the English Language Teaching Objectives are available or not in the General Secondary Certificate Examination Questions in Jordan in .... (e.g. available, unavailable).

\section{A- Listening}

\begin{tabular}{|l|l|l|}
\hline \multicolumn{1}{|c|}{ Objective } & Available & Unavailable \\
\hline $1-\quad \begin{array}{l}\text { Develop advanced listening strategies in academic and } \\
\text { authentic contexts. }\end{array}$ & & \\
\hline $2-\quad \begin{array}{l}\text { Demonstrate understanding of directions, presentations and } \\
\text { performances in a variety of authentic contexts. }\end{array}$ & & \\
\hline
\end{tabular}

\section{B- Speaking}

\begin{tabular}{|c|c|c|}
\hline \multicolumn{1}{|c|}{ Objective } & Available & Unavailable \\
\hline $1-\quad \begin{array}{l}\text { Speak English words and sentences clearly, and fluently in a } \\
\text { variety of academic authentic contexts. }\end{array}$ & & \\
\hline $2-\quad \begin{array}{l}\text { Use words and sentences to participate in discussions and } \\
\text { conversations in a variety of academic authentic contexts }\end{array}$ & & \\
\hline $3-\quad \begin{array}{l}\text { Take part in a variety of well- prepared presentations to the } \\
\text { class in a variety of academic authentic contexts. }\end{array}$ & & \\
\hline
\end{tabular}

\section{C-Reading}

\begin{tabular}{|c|c|c|}
\hline \multicolumn{1}{|c|}{ Objective } & Available & Unavailable \\
\hline $1-\quad \begin{array}{l}\text { Use reading strategies to understand a variety of authentic } \\
\text { informational and literary texts. }\end{array}$ & & \\
\hline $2-\quad \begin{array}{l}\text { Demonstrate understanding of a variety of authentic } \\
\text { informational and literary texts (e.g., applications, social and } \\
\text { scientific reports, academic essays, plays, and poems) }\end{array}$ & & \\
\hline 3- $\begin{array}{l}\text { Make connections between prior knowledge and experiences } \\
\text { and a variety of authentic informational and literary texts } \\
\text { (e.g., applications, social and scientific reports, academic } \\
\text { essays, plays, and poems). }\end{array}$ & & \\
\hline
\end{tabular}




\section{D-Writing}

\begin{tabular}{|c|l|l|}
\hline \multicolumn{1}{|c|}{ Objective } & Available & Unavailable \\
\hline $1-\quad \begin{array}{l}\text { Gather information and ideas from print and electronic } \\
\text { sources to organize and write in a variety of advanced } \\
\text { authentic contexts. }\end{array}$ & & \\
\hline $2-\quad \begin{array}{l}\text { Write a series of paragraphs for a variety of advanced } \\
\text { authentic purposes and audiences such as summaries, essays, } \\
\text { resumes, and multi-media presentations. }\end{array}$ & & \\
\hline $3-\quad \begin{array}{l}\text { Use appropriate organizational patterns to create authentic } \\
\text { advanced written work. }\end{array}$ & & \\
\hline 4- $\begin{array}{l}\text { Apply knowledge of the conventions of language (e,g., } \\
\text { spelling, punctuation, grammar, and usage) }\end{array}$ & & \\
\hline 5- $\begin{array}{l}\text { Revise written work for accuracy, clarity, correctness and } \\
\text { coherence with the assistance of teacher, peers, and } \\
\text { electronic programs. }\end{array}$ & & \\
\hline
\end{tabular}

The Researcher

Mahmoud Sulaiman Bani Abdel-Rahman 